peripheral means of treating gynic diseases the central or centrifugal one of a proper diet should not be neglected." And again, "sweets are at a premium because of ethical esthetic taste. Women grown on society diet can not have full development. Hence, in my opinion, the decline of the birth rate," etc. The birth rate probably is diminishing under this kind of thing and the jury should look to it, taking care that the State suffer no injury. Oatmeal is not the only paralyzing food in the United States.

The psycho-physical man asks of the Jourat : What distinguishes the practice of our profession in treating the diseases and repairing the injuries of the genus homo from that of the veterinarian? Thereafter he affirms "that excessive feelings of displeasure, when protracted, produce a deficiency of innervation and quite a list of pathologic conditions have been attributed to this cause, e.g., muscular debility, dyspnea, typhus, amenorrhea, chlorosis, dropsy, scurvy, tuberculosis, scirrhosis and medulla sarcoma." The placing of "medulla sarcoma" in such a list as that is probably a menace to public health. But that is a question of fact for the jury while they are engaged with the matter of drawing the line between veterinary medicine and psycho-physics. Let us have the jury. The woods are full of medical cases which otherwise will fail of proper adjudication. Medical men demand it. Legal men would hail it with joy. Ecclesiastical men would find in the operations of such a tribunal the beneficence without the terrors of the holy office.

TEXAS M.D.

\section{Railroad Rates.}

Flint, Mich., April 9, 1894.

To the Editor:-I wish to emphasize all that Dr. Daniel - Lichty, of Rockford, says in your issue of the 7th inst., in reference to railroad transportation for members of our Association and their families, who have in the past, and who want to attend in the future the an nual meetings of the Association.

Joining the Association myself at the New Orleans meeting in 1869, and attending its annual gatherings quite regularly for several years thereafter, I found that the comparatively small rebate in railroad fares afforded members, together with the neoessary drafts upon time and purse, were a serious consideration when contemplating a trip to the place of meeting, each year, and have been among the absentees for several years past.

The first meeting of the Association in San Francisco was held when money was plenty and the U. P. and C. P. railroads were new, and the desire to see these roads, the vast tract of diversified country through which they were made, coupled with a desire to see the metropolis of the Pacific Coast, induced many physicians to put forth great efforts to attend that meeting. But much of this is now changed, and I greatly fear that, unless a tempting fare is offered to us, we may remain at our posts, still, doing more than any other class of people to ameliorate the condition of mankind, and thereby rendering a service directly and indirectly which, in over forty-five years of practice, I have found railroads loth to acknowledge and appreciate.

Henry C. Fairbank, M.D.

\section{Rates to San Francisco.}

Pittsibur, PA., April 10, 1894.

To the Editor:-Considerable space has already been taken up in the JourNal on the subject of transportation to the Association meeting, and I am reluctant to presume upon you, but I feel that unless there are some concessions made on the part of the railroad authorities the attendance from the East will be very small. I interested myself some time since in getting up a party to go by special train, with the expectation of low rates, and had secured the names of fiftysix. To-day with the present prospect of increased rates $I$ can only get twelve of this same company to say they will go. Leaving out of consideration the fact that perhaps to no other body of men are the railroad companies under greater obligations than to the medical fraternity, as a matter of business, looking at it in a mercenary manner, it would pay them to reduce the rates one-half on account of the larger number of passengers.

Can not a more determined effort be made to make the rates more satisfactory?

Yours sincerely, John Milton Duff, M.D.

\section{Refilled Prescriptions.}

Ruston, La., April 11, 1894

To the Editor:-Has a druggist the right to refill a formula for a patient without the knowledge or consent of the physician? Has the patient the right to obtain a copy of formula from the druggist without the knowledge or consent of the author? In the event the patient is going to leave the community and take up residence in some distant part, has he the right then to obtain a copy of formula, and has the druggist the right to give it with the knowledge of the prescriber? Very respectfully, R. F. H.

\section{Endorses Dr. Cohen et alii.}

Dexver, Col., March 19, 1894.

To the Editor:-There are members of the Association outside of Pennsylvania who indorse most cordially Dr. Cohen's recent criticism of the policy of the Jourvar in regard to advertisements of proprietary articles. I, for one, give an unqualified assent to all that he has said, and in addition consider the editorial attitude of the Medical News and the Pittsburg Medical Review most commendable. They take the only stand that honorable adherents of our Code of Ethics can take. Very respectfully, WM. P. MunN, M.D.

\section{Supports Dr. Cohen.}

Alsa, Mich., March 19, 1894.

To the Editor:-Please record me as an ardent supporter of Dr. Solis-Cohen's contention against advertising quack remedies in our Journal. Yours,

I. N. Brainerd.

\section{BOOK NOTICES.}

\section{The International Medical Annual and Practitioner's Index: A} Work of Reference for Medical Practitioners. Edited by W. AlexaNDER, M.D., F.R.C.S., and thirty-nine collaborators. New York : E. B. Treat. 1894. Price \$2.75.

This is the American edition of the well-known Annual published in Bristol, England, for the last twelve years. The object of the Annual is to present its readers with "an exact and impartial record of the advances of medical science." In the rather successful effort to make the work truly cosmopolitan, the Annual has for some years past included among its contributors many American writers. For this volume we note the names of Hobart A. Hare, Wm. T. Buell, Paul F. Mundé, G. M. Hammond, H. D. Chapin, E. F. Frost, Frank W. Jackson, John Ridlon, J. Madison Taylor, Irving S. Haynes and John B. Hamilton. The Annual does not assume to make a report on all the medical literature of the preceding year, but takes note only of the "advances," or the progress made in medical knowledge of the subjects within the scope of the work.

Charaka-Samhita, Translated into English. Published by Avinash Chandra Kaviratna, Calcutta. Part VIII.

In our issue of September 23, we commented editorially on the character of this work, its great antiquity and its interest to all physicians.

This fasciculus concludes the nineteenth lesson, and gives 